\title{
Differences Description of the Two Different Squares of Taksim Turkey and Vatican Rome in View of Architectural Design Criteria
}

\author{
Kevser Inc1 Erturk \\ Mimar Sinan Fine Arts University, Istanbul 34427, Turkey
}

\begin{abstract}
Principles applied to the elements of design that bring them together into one design. This research distinguishes about the architectural design criteria and the comparisonal methods of two squares; one is Taksim in Turkey and in Vatican Sen Petro Square in Rome.
\end{abstract}

Key words: Hatching, inhabitant, substrate two dimentional surface.

\section{Introduction}

Principles applied to the elements of design that bring them together into one design. How one applies these principles determines how successful a design may be Ref. [1]. A line is a fundamental mark or stroke used in drawing in which the length is longer than the width. Two connected points form a line and every line has a length, width, and direction if it is straight [2]. This research distinguishes about the architectural design criteria. This image contains contour lines (the outline of the birds) and decoration lines (hatching). Uses a line that defines or bounds an edge, but not always the outside edge, could represent a fold or color change [3]. The comparison of two different squares will give the different design properties, but it must show us the familiar design conditions in high density of inhabitant.

\section{Method and Material}

A line that defines the edge of space can also be created by a gap of negative space. Many uses include to separate columns, rows of type, or to show a change in document type. Lines are used in linear

\footnotetext{
Corresponding author: Kevser Inc1 Erturk, Ph.D., research fields: architectural design. kevser.erturk@msgsu.edu.tr.
}

shapes and patterns to decorate many different substrates, and can be used to create shadows representing tonal value, called hatching.

Color can play a large role in the elements of design [4] with the color wheel being used as a tool, and color theory providing a body of practical guidance to color mixing and the visual impacts of specific color combination. Color star contains primary, secondary, and tertiary colors. Uses color can aid organization to develop a color strategy and stay consistent with those colors [4]. It can give emphasis to create a hierarchy and the piece of art.

Values and tints and shades of colors that are created by adding black to a color for a shade and white for a tint. Creating a tint or shade of a color reduces the saturation [4]. Saturation gives a color brightness or dullness [4].

A shape is defined as an area that stands out from the space next to or around it due to a defined or implied boundary, or because of differences of value, color, or texture [5]. All objects are composed of shapes and all other "Elements of Design" are shapes in some way [3].

Mechanical shapes or geometric shapes are the shapes that can be drawn using a ruler or compass. Mechanical shapes, whether simple or complex, 
produce a feeling of control or order. Organic shapes are freehand drawn shapes that are complex and normally found in nature. Organic shapes produce a natural feel.

The tree's visual texture is represented here in this image. Meaning the way a surface feels or is perceived to feel. Texture can be added to attract or repel interest to an element, depending on the pleasantness of the texture [3]. Types of texture Tactile texture is the actual three-dimension feel of a surface that can be touched. Painter can use impasto to build peaks and create texture [3].

Visual texture is the illusion of the surfaces peaks and valleys, like the tree pictured. Any texture shown in a photo is a visual texture, meaning the paper is smooth no matter how rough the image perceives it to be. Most textures have a natural touch but still seem to repeat a motif in some way. Regularly repeating a motif will result in a texture appearing as a pattern [3].

In design, space is concerned with the area deep within the moment of designated design; the design will take place on. For a two-dimensional design space concerns creating the illusion of a third dimension on a flat surface [3].

Overlap is the effect where objects appear to be on top of each other. This illusion makes the top element look closer to the observer. There is no way to determine the depth of the space, only the order of closeness. Shading adds gradation marks to make an object of a two-dimensional surface seem three-dimensional. Highlight, transitional light, core of the shadow, reflected light, and cast shadow give an object a three-dimensional look [3]. Linear perspective is the concept relating to how an object seems smaller the farther away it gets. Atmospheric perspective is based on how air acts as a filter to change the appearance of distance objects.

Form is any three dimensional object. Form can be measured, from top to bottom (height), side to side (width), and from back to front (depth). Form is also defined by light and dark. There are two types of form, geometric (man-made) and natural (organic form). Form may be created by the combining of two or more shapes. It may be enhanced by tone, texture and color. It can be illustrated or constructed.

Principles applied to the elements of design that bring them together into one design. How one applies these principles determines how successful a design may be Ref. [2].

According to Alex White, author of The Elements of Graphic Design, to achieve visual unity is a main goal of graphic design. When all elements are in agreement, a design is considered unified. No individual part is viewed as more important than the whole design. A good balance between unity and variety must be established to avoid a chaotic or a lifeless design [4].

\subsection{Design Rules}

Proximity: sense of distance between elements;

Similarity: ability to seem repeatable with other elements;

Continuation: the sense of having a line or pattern extend;

Repetition: elements being copied or mimicked numerous times;

Rhythm: is achieved when recurring position, size, color, and use of a graphic element has a focal point interruption.

Altering the basic theme achieves unity and helps keep interest.

Balance, is a state of equalized tension and equilibrium, which may not always be calm [4].

Types: the top image has symmetrical balance and the bottom image has asymmetrical balance.

Symmetry: Asymmetrical produces an informal balance that is attention attracting and dynamic. Radial balance is arranged around a central element. The elements placed in a radial balance seem to "radiate" out from a central point in a circular fashion. Overall is a mosaic form of balance which normally arises from too many elements being put on a page. 
Due to the lack of hierarchy and contrast, this form of balance can look noisy.

Hierarchy: A good design contains elements that lead the reader through each element in order of its significance. The type and images should be expressed starting from most important to the least [4].

Scale/proportion: Using the relative size of elements against each other can attract attention to a focal point. When elements are designed larger than life, scale is being used to show drama [4].

Dominance/emphasis: Dominance is created by contrasting size, positioning, color, style, or shape. The focal point should dominate the design with scale and contrast without sacrificing the unity of the whole [4].

\subsection{Similarity and Contrast}

Planning a consistent and similar design is an important aspect of a designers work to make their focal point visible. Too much similarity is boring but without similarity important elements will not exist and an image without contrast is uneventful so the key is to find the balance between similarity and contrast [4].

Similar environment: There are several ways to develop a similar environment [4]. Build a unique internal organization structure. Manipulate shapes of images and text to correlate together. Express continuity from page to page in publications. Items to watch include headers, themes, borders, and spaces. Develop a style manual and stick with the format.

\section{Contrasts}

Space Filled/Empty

Near/Far

2-D/3-D

Position Left/Right

Isolated/Grouped

Centered/Off-Center

Form Simple/Complex

Beauty/Ugly

Whole/Broken

Direction Stability/Movement
Structure Organized/Chaotic

Mechanical/Hand-Drawn

Size Large/Small

Deep/Shallow

Fat/Thin

Color Grayscale/Color

Light/Dark

Texture Fine/Coarse

Smooth/Rough

Sharp/Dull

Density Transparent/Opaque

Thick/Thin

Liquid/Solid

Gravity Light/Heavy

Stable/Unstable

Movement is the path the viewer's eye takes through the artwork, often to focal areas. Such movement can be directed along lines edges, shape and color within the artwork.

See also,

Portal icon design portal

Composition (visual arts)

Interior design

Pattern language

Elements of art

Principles of art

Color theory

Comparisonal properties of two different square

Taksim Square (Turkish: Taksim Meydan1), situated in the European part of Istanbul, Turkey, is a major tourist and leisure district famed for its restaurants, shops, and hotels. It is considered the heart of modern Istanbul, with the central station of the Istanbul Metro network. Taksim Square is also the location of the Monument of the Republic (Turkish: Cumhuriyet Anit1) which was crafted by Pietro Canonica and inaugurated in 1928. The monument commemorates the 5th anniversary of the foundation of the Republic of Turkey in 1923, following the Turkish War of Independence.

The word Taksim means "division" or 
"distribution". The Taksim square was originally the point where the main water lines from the north of Istanbul were collected and branched off to other parts of the city (hence the name). This use for the area was established by Sultan Mahmud I. The square takes its name from the Ottoman era stone reservoir which is located in this area. Additionally, on the other hand, the word "Taksim" can refer to a special improvisational musical form in Turkish classical music that is guided by the Makam system.

In front of the water reservoir (Maksem) at Taksim Square was built and also a water pool was put in 1940. After then they decided to build an opera building at this square. The construction begun at 1946, postponed finishing it during 13 years and it was completed and opened at the year 1969.

Another significant building that once stood on the square was the 19th century Taksim Artillery Barracks (TaksimTopçu Kışlası, which later became the Taksim Stadium), but it was demolished in 1940 during the construction works of the Taksim Park (Taksim Gezi Park1) 5.

Taksim is a main transportation center and a popular destination for both tourists and the native population of Istanbul. İstiklal Caddesi (Independence Avenue), a long pedestrian shopping street, ends at this square, and a nostalgic tram runs from the square along the avenue, ending near the Tunel (1875) which is the world's second-oldest subway line after London's Underground (1863). Numerous travel agencies, hotels, restaurants, pubs, and international fast food chains such as Pizza Hut, McDonald's, Subway, and Burger Kingare are located in Taksim Square. It is also home to some of Istanbul's grandest hotels including the Inter Continental, the Ritz-Carlton, and The Marmara Hotel.

Taksim is also a favourite location for public events, New Year celebrations, or other social gatherings. Atatürk Cultural Center (Atatürk Kültür Merkezi), a multi-purpose cultural center and opera house, is also located at Taksim Square. Taksim square is a sign of symbol of Turkish Republic. The Red Square in the Russia, Tiennanmen squares in China, Athens Sytagma square in Greece, Trafalger Square in London, Time Square in New York and Concorde square in Paris which are not so important by comparing with Taksim Square for politicians and historical point of view it is more important. The Pera side of Istanbul is part of the Urban which is sustainable as Western Life style. Taksim Square has a history along the 19th Century first part which continues till today. The Grand Rue de Pera has the biggest the Galata Dervish House (Mevlevihane) in Islamic cultural building and finishes on the other side with Taksim Water Reservoir (Taksim Maksen). In front of this Maksen there was a natural platform. At the beginning of 19th Century Topcu Kislasi (Royal Army House) was built at the North-East of the Natural Platform. Topcu Kislasi is a square building and has an atrium at the center of the building. It has eclectics in the Islamic Architectural style which depends to the North-Africa. There were located horse stalls between Cumhuriyet Monument and Green Area, which are continuous situation on the Green Area and Cumhuriyet Monument. The Cadde-I Kebir (street which comes from Pera) is located between the Horse stalls and Maksen. The first step for the establishment of the today's square was beginning with building of the Republic Monument. The Design of Environment was established by Italian Architect Giulio Mongeri (7) designed the Neoclassic Eclectics Building by Neo Byzantion units. On the beginning of this age the tramway is surrounded around this monument which comes from Independency Street (Istiklal Caddesi). In front of these horse stalls caffee houses were built. There is a famous coffee house which was known as Eftalopos at the end of 19th Century. The Ataturk Monument was built by Italian Sculptures Pietro Canonica. One French architect and urban planners Henry Prost [6] was invited to make a main plan for Istanbul. In this plan which is accepted by Istanbul Metropolitan Municipality in 1939, instead of 
Differences Description of the Two Different Squares of Taksim Turkey and Vatican

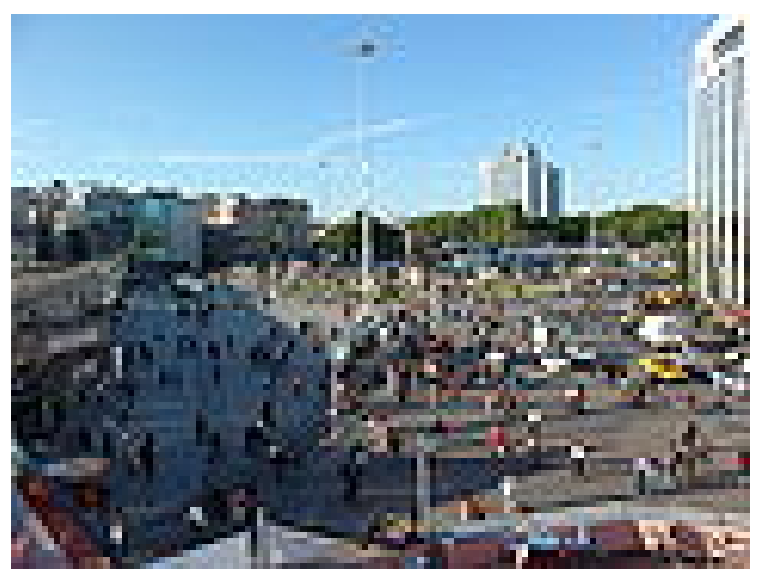

Fig. 1 Taksim Square, http://upload.wikimedia.org/wikipedia/commons/thumb/4/4f/TaksimSquareIstanbul.jpg/800pxTaksimSquareIstanbul.jpg

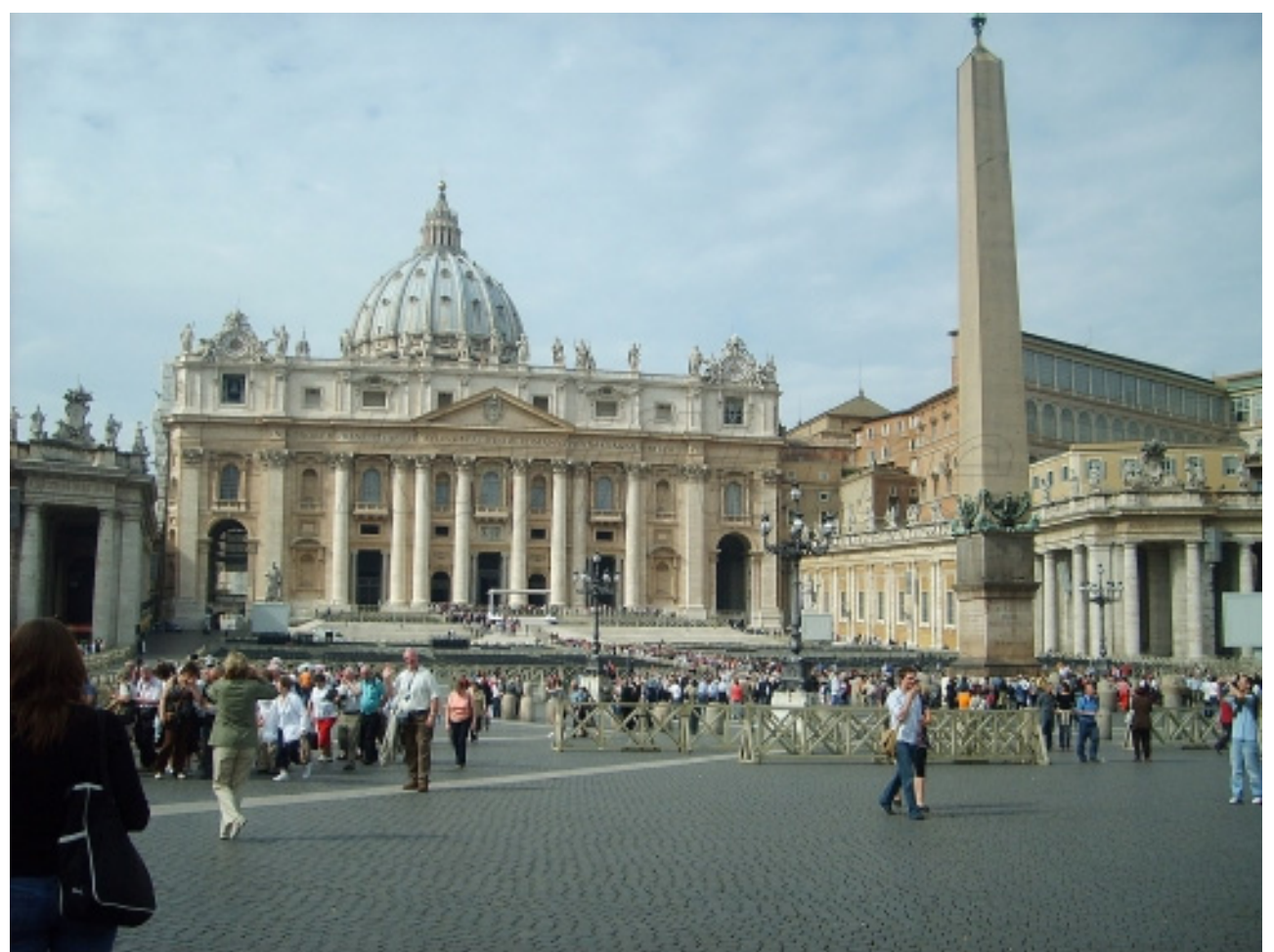

Fig. 2 San Pietro Square in Vatican by Plan and Cross Section.

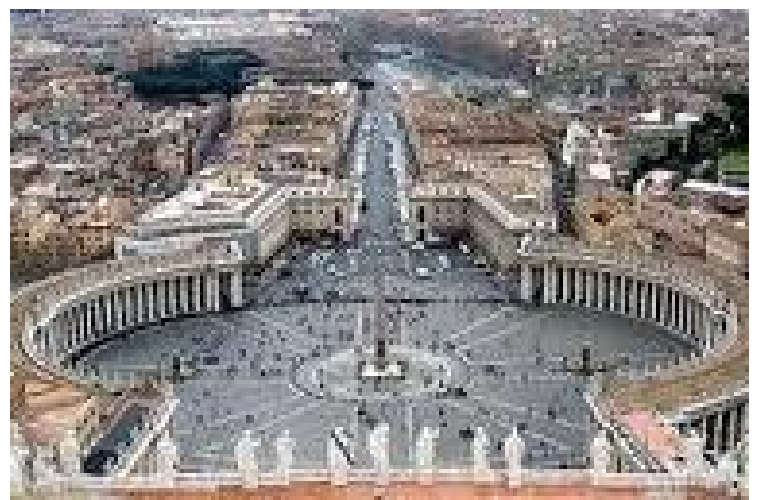

Fig. 3 San Pietro Square in Vatican by Plan and Cross Section. 
the Royal Army House (Topçu Kışlası) the Green Area was established. After this plan, this building is diminished. It appears a wide and green area and the Republic Monument was located on one edge of the Taksim square. In the Year of 1993 the Independecy Street (Istiklal Caddesi) was changed as walking Zone. At the beginning of the 20th Century, this square has a mobility character with the spectacular Balcony by famous Levanten Architect Alexander Valery [6]. In 1970 the Marmara Taksim Hotel is added to this square. In spite of during this process to Taksim Square lost from his meaning many things it becomes the focus point of the Republic on the social life.

NTV television had its morning news studio on Taksim Square for a number of broadcasting seasons, before moving to its new studio in 2011.

The Square of Vatican San Pietro is identified for finding the necessary space buildings like shopping and entertainment and for pray, conservated heritage and culture of the own country.

\section{Consequences}

The square of Vatican is the center of Christians (Catholic) religion. By comparison this square with Taksim square at the centre of Taksim square there is monument of Ataturk, and in Vatican square there is a historical column monument which is located the central point. The plan is contributed as line which comes from the central point. The traffic way comes to one edge of the Vatican Square and acts like a gate.

In comparison this square with Taksim, this square lost his central contributed plan properties by changing with the new Taksim plan orders. Taksim Square has in one edge a wider and greener healty habitat area. Now, this habitat area should be ordered in scope of healty relations with small shopping touristical buildings.

Vatican square (Vatican San Pietro Square) is the centre of Christians, it has a holly meaning which has collected the people surrounded by a religious aim. This square of Vatican San Pietro includes has San Pietro Building and Cistine Scapel. Their walls are embellished by the sculptures which tell the story of Christian's birth. This official space supported gathering the people. Taksim Cumhuriyet square is the symbol of the Turkish Republic. Taksim square is one of the important squares like Beyazıd and Sultan Ahmet square in our political history but it is not so important like in Moscow Kremlin square in Russia, Tienman square in China, Athens Sytagma square in Greece, Trafalger Square in London, Time Square in New York and Concorde square in Paris. Taksim Cumhuriyet square has the identity of the political and coming together symbol and it has to conserve and protect its sustainability and its conservation. Here can be discussed the culture and the secular, political and democratic ideas by the people and NGO's defined their wishes and hopes. By comparing of these two different squares they have different functions and designs. Taksim square has a character of discussing the democracy, and independency ideas and dominant lines and it is the product of a flexible design. The urban and open squares cannot be met in Islamic countries but it can be seen in European open squares except Tahrir square in Cairo and Azadi Square in Tehran. These squares are employed by themselves during the time.

\section{References}

[1] Lidwell, W., Holden, K., and Butler, J. 2010. Universal Principles of Design (2nd ed.). Beverly, Massachusetts: Rockport Publishers.

[2] Lovett, J. 2012. "Design and Color."

[3] Saw, J. 2012. "Design Notes." Palomar College.

[4] White, A. 2011. The Elements of Graphic Design. New York: Allworth Press.

[5] http://www.en.wikipedia.org.

[6] Can, C. 1993. Yüzyılbatılıve Levanten Mimarların Korumasorunları (Doktora Tezi) YTU.

[7] Çelik, Z. 1996. Değişen Istanbul. 